\title{
Examining Nutrition and Physical Activity Policies and Practices in Maryland's Child Care Centers
}

\author{
Kristin Bussell, MS, CRNP, Lucine Francis, PhD, RN,2 Bridget Armstrong, PhD, \\ Sarah Kilby, $\mathrm{MPH}^{4}$, Maureen M. Black, $\mathrm{PhD}^{3,5}$ and Erin R. Hager, $\mathrm{PhD}^{3}$
}

\section{Abstract}

Background: Child care settings provide opportunities for obesity prevention by implementing nutrition/physical activity best practices. This study examines how center policies, provider training, family education, and center demographics relate to best practices for nutrition/physical activity in Maryland's child care centers.

Methods: A survey, including minor modifications to The Nutrition and Physical Activity Self-Assessment for Child Care (Go NAP SACC), was sent by e-mail to center directors statewide. Best practice sum scores (dependent variable) were calculated, including physical activity (17 items), feeding environment (18 items), and food served (19 items). Adjusted regression models analyzed the number of nutrition/physical activity policies, provider training topics, and family education opportunities related to best practice scores.

Results: Response rate was 40\% ( $n=610 / 1506)$ with 69\% independent centers (vs. organization sponsored), 19\% with Child and Adult Care Food Program (CACFP enrolled), and 50.2\% centers with majority ( $\geq 70 \%$ ) Caucasian children and $16.8 \%$ centers with majority African American children. Centers reported $40.8 \%$ of physical activity best practices, $52.0 \%$ of feeding environment best practices, and $51.6 \%$ of food served best practices. Centers reported (mean) 7.9 of 16 nutrition/physical activity-relevant policies, 6.9 of 13 provider training topics, and 4.4 of 8 family education opportunities. Regression models yielded associations with best practices: policies and provider training with feeding environment $(\mathrm{B}=0.26, p<0.001 ; \mathrm{B}=0.26, p=0.001$, respectively); policies with foods served $(\mathrm{B}=0.22, p=0.002)$; and policies, provider training, and feeding environment with physical activity $(\mathrm{B}=0.19$, $p=0.001 ; \mathrm{B}=0.24, p=0.010 ; \mathrm{B}=0.38, p<0.001)$.

Conclusions: Nutrition/physical activity best practices in child care are supported by specific policies, provider training, and family education activities.

Keywords: child care; early care and education; feeding; nutrition; physical activity; policy

\section{Background}

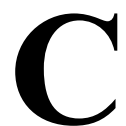

hildhood obesity increases the risk for chronic diseases, including early-onset cardiovascular disease, type 2 diabetes mellitus, and sleep disorders. ${ }^{1-3}$ In the United States, $13.9 \%$ of children ages $2-5$ years are obese, ${ }^{4}$ with increased rates among low-income and ethnic minority preschoolers. Data from the Special Supplemental Nutrition Program for Women, Infants, and Children Parti- cipants and Program Characteristics (WIC PC) are used by the Centers for Disease Control to track the prevalence of obesity among children ages 2-4 years from low-income families. ${ }^{5}$ In 2014, the prevalence of obesity from WIC PC was $14.5 \%$ (specifically, $18.0 \%$ American Indian/Alaskan Native, $17.3 \%$ Hispanic, $12.2 \%$ non-Hispanic white, $11.9 \%$ non-Hispanic black, and $11.1 \%$ Asian/Pacific Island children). Maryland's population is diverse (51.5\% non-Hispanic white, $30.7 \%$ non-Hispanic black, 9.8\%

\footnotetext{
'Department of Family and Community Health, University of Maryland School of Nursing, Baltimore, MD.

2Johns Hopkins School of Nursing, Baltimore, MD.

${ }^{3}$ Department of Pediatrics, University of Maryland School of Medicine, Baltimore, MD.

${ }^{4}$ Maryland State Department of Education, Baltimore, MD.

${ }^{5} \mathrm{RTI}$ International, Research Triangle Park, NC.
} 
Hispanic, and $6.6 \%$ Asian $^{6}$ ) offering the opportunity to gather information from child care centers serving a racially and ethnically diverse population.

More than 10 million US children ages $0-5$ years are enrolled in child care, with many children consuming 2-3 meals/day and participating in physical activity through structured and unstructured play, ${ }^{7}$ creating a unique opportunity for providers to influence children in developing healthy eating and physical activity (HEPA) habits. The National Resource Center for Health and Safety in Child Care and Early Education has established standards based on the Dietary Guidelines for Americans 2010 and national Child and Adult Care Food Program (CACFP) requirements $^{7}$ (a federal program that subsidizes meals to child care centers serving low-income families ${ }^{8}$ ). In Maryland, all licensed child care centers that serve food are required to comply with CACFP standards, ${ }^{9}$ however, compliance is assessed only among CACFP-enrolled centers. Federal law does not mandate physical activity time or limits to sedentary time in child care. Beginning in 2016 (after completion of this study), Maryland state law required planned daily activities, sufficient materials/equipment for physical activity, and limits on screen time. ${ }^{10}$ The Nutrition and Physical Activity Self-Assessment (NAP SACC) was developed by childhood obesity researchers to assist child care center compliance with standards and guidelines. ${ }^{11}$ In 2015, the NAP SACC was revised via inclusion of additional content areas (i.e., screen time and outdoor play) and updated recommendations (called "Go NAP SACC"). ${ }^{12,13}$ This tool is commonly used by researchers to assess nutrition and physical activity policies and practices in child care centers. ${ }^{14-16}$

Recent studies and national reports suggest variability in the implementation of nutrition and physical activity policies and practices. A 2016 report on child care licensing regulations found that only $20 \%$ of US child care centers fully met "healthy weight practice" regulations. ${ }^{17}$ Multiple studies found that child care centers serve high-sugar/ sodium/fat foods, provide minimal fruits/vegetables and whole grains, with limited access to water. ${ }^{18-20}$ Although most centers report limiting screen time and providing physical activity opportunities, a recent study found only one-third had written policies in place. ${ }^{21}$ Variation in physical activity practices is common, affected by availability of outdoor play space, play equipment, and weather conditions; indoor physical activity is often substituted with sedentary play or screen time. ${ }^{22-24}$ Beyond a description of practices, there is limited information on the implementation of nutrition and physical activity policies and practices in child care.

The Social Ecological Model is a useful framework to examine how environmental factors relate to the implementation of nutrition and physical activity policies and practices in child care..$^{25,26}$ The interplay among ecological levels is a key element of the Social Ecological Model. ${ }^{25}$ For example, child care center policies may relate to individual health behaviors through the interplay across ecological levels, including policy implementation within classrooms or teacher/family reinforcement of messaging. This study examines how center policies, provider training, and family education relate to the implementation of nutrition and physical activity best practices in child care centers.

Beyond federal and state-specific nutrition and physical activity policies for child care, each center may develop center-level policies, similar to school district wellness policies in place for schools since $2006 .{ }^{27}$ There is limited literature on child care center policies and policy implementation, ${ }^{28}$ however, initiatives have begun in large organization-sponsored centers. For example, in 2011, the YMCA of the United States developed HEPA standards to be implemented in its sponsored child care centers, ${ }^{29}$ however, the implementation and impact of these standards have not been reported. Additional research is needed to examine associations between center-level policies and nutrition/physical activity best practices.

Nutrition/physical activity training for early child care providers has been shown to increase children's consumption of healthy foods and physical activity ${ }^{30-33}$ by equipping them to build healthy habits into children's daily activities. Yet, a recent systematic review noted that additional studies are needed to fully understand the role of provider training in health promotion in child care. ${ }^{34}$

Families of young children are essential partners in child care health promotion efforts through creating a home environment that complements a health-promoting child care environment. ${ }^{35}$ Engaging families to increase knowledge and opportunities for HEPA behaviors has been shown to strengthen child care interventions and improves children's anthropometric outcomes. ${ }^{36-39}$ Child care centers may facilitate this partnership through family engagement opportunities, which may support overall nutrition and physical activity best practices in child care centers.

In addition to examining center policies, provider training, and family education, the demographic characteristics of families served by centers may also relate to nutrition/physical activity best practices. Few studies have examined demographic characteristics of the children served by centers.

The purpose of this study is to examine how center policies, provider training, family education, and center demographics relate to best practices for nutrition (specifically, the feeding environment and foods served) and physical activity in Maryland's child care centers.

\section{Methods}

\section{Sample}

Maryland child care centers (actively licensed in 2014), providing care for children ages $0-5$, were included (exclusion criteria: before or afterschool only or home-based day care). Contact information for 2690 licensed centers or before/afterschool care sites was provided by the state department of education. Verification of contact information, 
removal of duplications, and eligibility determination resulted in inclusion of 1506 centers (primary reason for exclusion: only offer before/after care for school aged children). An e-mail survey link (SurveyMonkey, San Mateo, CA) was sent to the points of contact for all centers, specifying that the survey be completed by the director or a person knowledgeable about the center's nutritional policies and practices. An initial e-mail was sent followed by five reminder e-mails. The center staff completing the survey received one professional development hour as part of licensure requirements from the state department of education. Survey responses were accepted from December 2014 to February 2015. The protocol was approved by the Institutional Review Boards of the University of Maryland and Maryland Department of Health.

\section{Measures}

The survey included center-level demographics (19 items), which were used to generate center size (no. of children enrolled, dichotomized at 50 students or more/ less), organization sponsored (independent center or sponsored by a large organization, such as the YMCA), subsidy voucher acceptance (yes/no), CACFP participation (yes/no), and race/ethnicity of the student body [estimated percentages by race/ethnicity, almost none $(<10 \%)$, some $(1 \%-30 \%)$, half $(40 \%-60 \%)$, most $(70 \%-90 \%)$ or almost all $(>90 \%)$, used to generate two dummy variables for (1) most/all Caucasian and (2) most/all African American students vs. not].

Adapted questions from the Go NAP SACC were included in the survey (specifically, items from the child nutrition, child physical activity, outdoor play and learning, and screen time assessments). ${ }^{13}$ The online survey consisted of questions related to best practices for foods served, feeding environment, and physical activity, modified as follows:

1. Order of response options listed least to greatest (original: last item was best practices, therefore response option magnitude fluctuated; e.g., healthy foods were listed least to greatest, whereas unhealthy foods were listed greatest to least).

2. Expanded response options to include never vs. rarely, rather than combining never/rarely as in the original.

3. Separation of items that represented multiple constructs (dark green and dark orange vegetables; red and deep yellow vegetables).

For this analysis, each item was dichotomized (best practices reported vs. not reported) and summed to create best practice sum scores for each construct.

Additional items slightly modified from the Go NAP SACC include six questions with checklist responses for (1) written nutrition policies, (2) written physical activity policies, (3) provider training for nutrition, (4) provider training for physical activity, (5) family education for nutrition and family education for physical activity. These were modified by asking participants to indicate which topic/ policy was covered (in the original, the response set includes a range of items, i.e., 0 topics, $1-4$ topics, and 5-8 topics). Reporting per topic is shown in Table 1. Each question was summed to generate a continuous score representing the number of policies/topics present/offered by a center.

To examine test-retest reliability, a subset of questions was repeated at the end of the survey. A subsample of 369 centers received physical activity questions twice, and 336 centers received nutrition/feeding questions twice. Spearman rank correlations (SCC) were significant for physical activity $(\mathrm{SCC}=0.85, p<0.001)$ and nutrition/feeding $(\mathrm{SCC}=0.80, p<0.001)$.

A scoring protocol was developed by applying scores of 1-4 (worst to best practice), mirroring the scoring protocol used for prior versions of the NAP SACC. ${ }^{40}$ A best practice sum score was calculated for each of the subscales: physical activity (17 items), feeding environment (18 items), food served (19 items). Cronbach's alpha was used to examine internal consistency of scales/subscales.

\section{Analyses}

All analyses were conducted in SPSS version 22.0 (IBM Corp., 2013). To examine relationships between demographic variables (independent variables, "IVs") and best practice scores (continuous, dependent variables, "DVs"), independent $t$ tests and analysis of variance (ANOVAs) with least significant difference (LSD) post hoc testing were used. Three separate regression models were conducted for each of the DVs to examine relationships with IVs [center demographics (dichotomous, entered together in step 1) and number of nutrition/physical activity-relevant center policies, number of provider training topics, and number of family education topics (continuous, entered together with demographics in step 2)].

\section{Results}

\section{Sample}

Of the 1506 surveys, 610 child care centers responded (40\%). Head Start centers were included, but based on low response rate $(3.6 \%, n=19)$ and significantly higher nutrition best practice scores compared with non-Head Start centers [feeding environment $t(626)=3.54, p<0.001$ and foods served $t(487)=2.04, p=0.02]$, they were excluded, leaving an analytic sample of 588. All 24 Maryland counties were represented.

Center characteristics (Table 2) found in more than two-thirds of centers were independent (vs. organization sponsored), had more than 50 children, and accepted subsidy vouchers (Table 2 ). Fewer than $20 \%$ participated in CACFP, a slightly lower proportion than typically observed statewide ( $\sim 30 \%$ of centers are CACFP enrolled in Maryland). Approximately $50 \%$ of centers had a student body of mostly $(\geq 70 \%)$ Caucasian students, $16.8 \%$ of centers had mostly $(\geq 70 \%)$ African American students, with the remaining centers having a diverse student body (33.0\% had no single-race majority). Centers 


\section{Table I. Nutrition/Physical Activity Center Policies, Provider Training,} and Family Education

\begin{tabular}{l|l|c|l}
$\begin{array}{l}\text { \% Reported } \\
\text { Written Center Policy }\end{array}$ & Nutrition \\
\hline 71.8 & Beverages provided to children & 51.9 & Not taking away PA to manage challenging behaviors \\
76.5 & Foods provided to children & 32.0 & Education for families on children's PA \\
14.8 & Nonfood fundraisers & 71.4 & $\begin{array}{l}\text { Amount of time provided each day for } \\
\text { indoor and outdoor PA }\end{array}$ \\
47.4 & Healthy mealtime environments & 41.8 & Limiting long periods of seated time for children \\
48.5 & Foods offered during holidays/celebrations & 54.8 & Planned and informal PA education \\
42.5 & Planned and informal nutrition education for children & 48.5 & Teacher practices that encourage PA \\
29.8 & Professional development on child nutrition & 74.1 & $\begin{array}{l}\text { Shoes and clothes that allow children and teachers } \\
\text { to actively participate in PA }\end{array}$ \\
51.5 & Teacher practices to encourage healthy eating & &
\end{tabular}

Provider training topics covered

\begin{tabular}{|c|c|c|c|}
\hline 58.2 & Communicating with families about child nutrition & 75.0 & Encouraging children's PA \\
\hline 58.5 & Food and beverage recommendations for children & 46.3 & $\begin{array}{l}\text { Communicating with families about encouraging chil- } \\
\text { dren's PA }\end{array}$ \\
\hline 62.4 & Creating a healthy mealtime environment & 65.0 & Limiting long periods of seated time for children \\
\hline 49.5 & Importance of variety in the child diet & 73.6 & Children's motor skill development \\
\hline 64.8 & Our program policies on child nutrition & 58.2 & Our program policies on $\mathrm{PA}$ \\
\hline 56.3 & Using positive feeding practices & 38.6 & Recommended amounts of daily PA for young children \\
\hline 61.2 & Serving sizes for children & & \\
\hline \multicolumn{4}{|c|}{ Family education topics covered } \\
\hline 54.6 & Food and beverage. recommendations for children & 65.3 & Children's PA included encouraging children's PA \\
\hline 52.7 & Creating a healthy mealtime environment & 61.7 & $\begin{array}{l}\text { Children's PA included children's motor } \\
\text { skill development }\end{array}$ \\
\hline 55.8 & Importance of variety in the child diet & 41.7 & $\begin{array}{l}\text { Children's PA included limiting long periods } \\
\text { of seated time for children }\end{array}$ \\
\hline 65.0 & Our program policies on child nutrition & & \\
\hline 47.6 & Using positive feeding practices & & \\
\hline
\end{tabular}

PA, physical activity.

that did not serve food $(\sim 10 \%)$ were not included in the food served best practice score. On average, centers reported $9.36(\mathrm{SD}=2.97)$ feeding environment best practices, 9.8 $(\mathrm{SD}=3.14)$ food served best practices, and $4.89(\mathrm{SD}=2.53)$ physical activity best practices, representing $52.0 \%, 51.7 \%$, and $40.8 \%$ of possible items reported, respectively.

\section{Feeding Environment Best Practices}

Associations between demographic variables and best practice scores are presented in Table 2. Organizationsponsored centers reported higher feeding environment best practice scores compared with independent centers. Remaining demographic factors were not associated with the feeding environment best practice score. Regression analyses are presented in Table 3. Race (two dummycoded variables; majority African American and majority Caucasian), organization sponsored, and CACFP participation were included as covariates. A number of center policies and provider training topics were related to feeding environment best practice, accounting for $20 \%$ of the variance in feeding environment score.

\section{Food Served Best Practices}

CACFP-participating centers had higher food served best practice scores in bivariate models (Table 2). In adjusted models, centers that were majority African American 
Table 2. Demographics by Nutrition and Physical Activity Practices

\begin{tabular}{|c|c|c|c|c|c|c|c|}
\hline & $\begin{array}{l}\text { In each } \\
\text { group (\%) }\end{array}$ & $\begin{array}{c}\text { Feeding } \\
\text { environment } \\
\text { best practices, } \\
\text { ( } n=588),(18 \text { total } \\
\text { best practices) }\end{array}$ & $t / F$ & $\begin{array}{c}\text { Food served } \\
\text { best practices, } \\
(n=529) \\
\text { (19 total best } \\
\text { practices) }\end{array}$ & $t / F$ & $\begin{array}{c}\text { PA best } \\
\text { practices, } \\
\text { ( } n=588), \\
\text { (I total best } \\
\text { practices) }\end{array}$ & $t / F$ \\
\hline Overall mean $\pm S D$ (range) & & $9.36 \pm 2.97(2-18)$ & & $9.80 \pm 3.14(2-19)$ & & $4.89 \pm 2.53(0-12)$ & \\
\hline Center size & & & 0.28 & & -1.72 & & -1.15 \\
\hline$>50$ Students & 64.8 & 9.38 & & 9.63 & & 4.80 & \\
\hline$<50$ Students & 35.2 & 9.30 & & 10.13 & & 5.05 & \\
\hline Organization sponsorship & & & $-2.39 *$ & & 0.18 & & 0.55 \\
\hline Independent & 69.0 & 9.16 & & 9.81 & & 4.85 & \\
\hline Organization sponsored & 31.0 & 9.79 & & 9.76 & & 4.97 & \\
\hline Subsidy voucher acceptance & & & 0.25 & & 0.43 & & 1.40 \\
\hline Accept & 73.1 & 9.34 & & 9.77 & & 4.80 & \\
\hline Not accept & 26.9 & 9.41 & & 9.91 & & 5.13 & \\
\hline CACFP participation & & & 0.91 & & $3.42 *$ & & -1.16 \\
\hline Not participating & 80.6 & 9.26 & & 9.61 & & 4.92 & \\
\hline Participating & 19.4 & 9.54 & & 10.68 & & 4.61 & \\
\hline Race/ethnicity of student body & & & 2.76 & & 1.84 & & $4.01 *$ \\
\hline Majority Caucasian ( $\geq 70 \%$ ) & 50.2 & 9.14 & & 9.88 & & $4.75^{\mathrm{a}}$ & \\
\hline Majority African American & 16.8 & 9.19 & & 9.26 & & $4.52^{b}$ & \\
\hline $\begin{array}{l}\text { Majority not Caucasian } \\
\text { or African American }\end{array}$ & 33.0 & 9.76 & & 9.98 & & $5.29^{a, b}$ & \\
\hline
\end{tabular}

a,bPairwise by group based on LSD multiple comparison test $(p<0.05)$.

$*_{p}<0.05$.

CACFP, Child and Adult Care Food Program; LSD, least significant difference; SD, standard deviation.

had lower food served best practice scores, while CACFPparticipating centers and centers with a greater number of center policies reported engaging in more food served best practices (Table 3 ). The final model accounted for $8 \%$ of the variation in food served best practice.

\section{Physical Activity Best Practices}

In bivariate models (Table 2), both centers with a majority of African American student body and with a majority of Caucasian student body reported lower physical activity best practice scores in comparison with racially diverse centers (Table 2). Regressions (Model 3, Table 3) revealed that both majority of African American student body and CACFP participation were associated with lower physical activity best practice scores. In addition, a number of center policies, provider training topics, and family education topics were all uniquely predictive of physical activity best practice score. The fully adjusted model (step 2) accounted for $23 \%$ of the variance in physical activity best practice score.

\section{Discussion}

This study sought to understand nutrition and physical activity best practices in a diverse, statewide sample of child care centers. Centers reported that they implemented approximately half of the nutrition (feeding environment and foods served) best practices and fewer than half of the physical activity best practices. Center demographics, nutrition/physical activity-relevant center policies, and number of provider training and family education topics offered by the center were each examined and, to some extent, associated with best practices.

CACFP participation was associated with a greater number of food served best practices, even though all licensed child care centers in Maryland that serve food are required to follow CACFP standards (compliance, however, is only assessed among CACFP-enrolled centers). ${ }^{9}$ Several studies have shown that CACFP-enrolled facilities are more likely to engage in healthy feeding practices compared with non-CACFP facilities. ${ }^{40-42}$ The current 
Table 3. Three Regression Models Predicting Feeding Environment, Food Served, and Physical Activity Best Practices

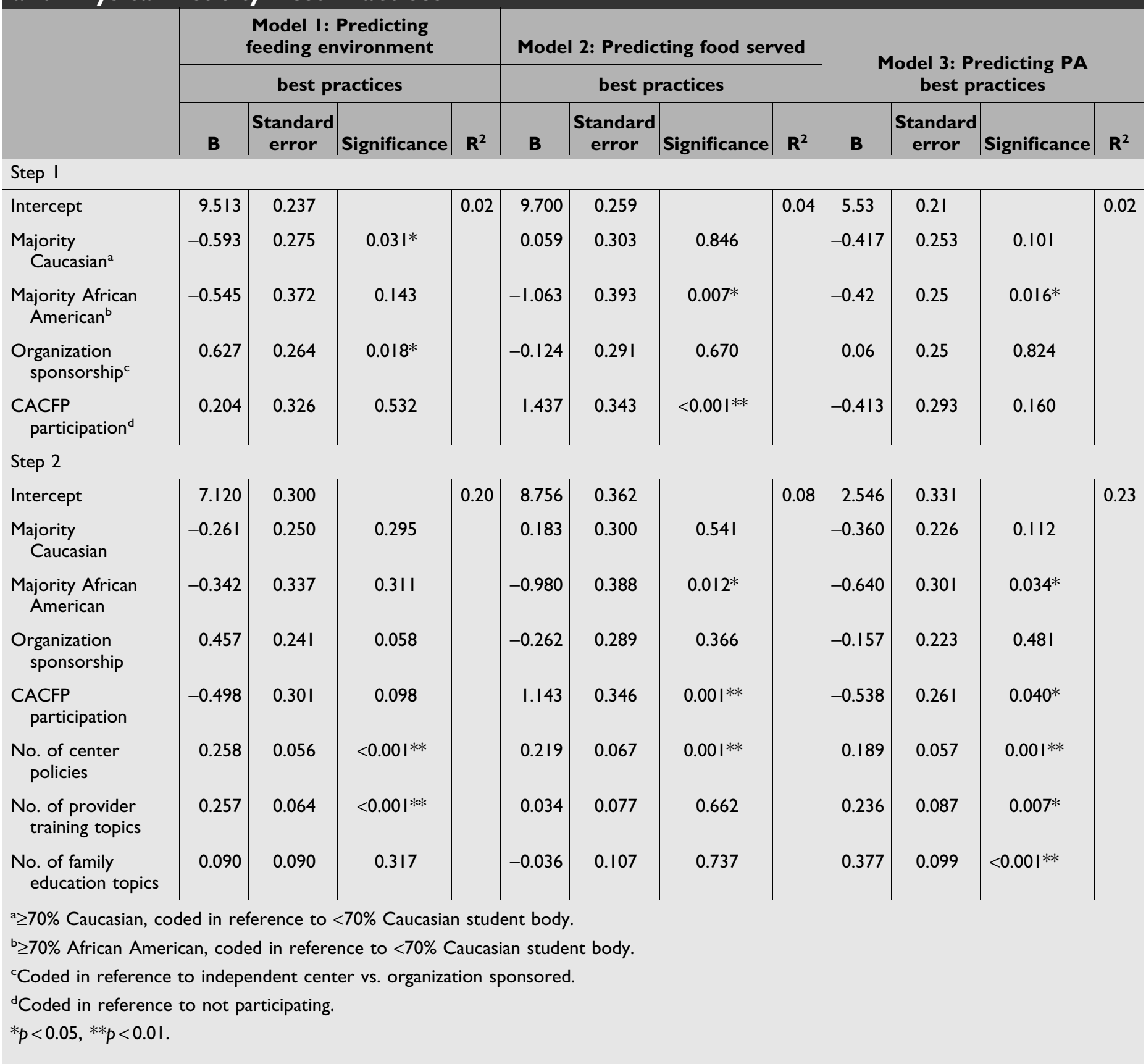

study and the existing literature support the importance of strong nutrition guidelines and oversight, both of which the CACFP provides.

The current study found that centers with a majority of African American student body reported fewer food served best practices and physical activity best practices, compared with centers without a majority of African American student body. Given the importance of culture in food, future studies should further explore the role of the race/ ethnicity of the student body as it relates to foods provided in child care centers.
Centers sponsored by a large organization reported more feeding environment best practices compared with independent centers. Organization-sponsored centers may have greater access to resources, supplies, and provider training opportunities to support a healthy feeding environment. Given the overall decentralization of child care centers (in comparison with schools, with school district oversight), strategies are needed to support independent centers in meeting best practices.

Centers that had more comprehensive nutrition/physical activity-relevant policies reported more best practices in 
all three areas (feeding environment, foods served, and physical activity). A growing body of research supports comprehensive wellness policies in child care to promote healthy weight practices. ${ }^{43,44}$ The federal government has mandated written wellness policies for school districts serving school-aged children that participate in USDA meal programs ${ }^{44}$ however, no such legislation exists in child care.

Training for child care providers is key to enhance provider knowledge and practices related to healthy weight in children and foster center policy development. ${ }^{30-33,36-38,45}$ Report of offering a greater variety of provider training opportunities was associated with more feeding environment and physical activity best practices in the current study, but not food served best practices. The decision of foods provided in a child care center setting is often made by the director or food service staff, and not the classroom providers, perhaps explaining this null funding. Additional research is needed related to specific training opportunities that are effective in supporting a health-promoting environment and knowledge around nutrition and physical activity.

Child care staff are often trained to address healthy center-based practices. However, the level of parent engagement needed to form collaborative relationships that promote healthy practices at both centers and homes is understudied. In the current study, family education opportunities were positively associated with meeting more physical activity best practices. Strategies to engage with parents are emerging, as shown by a study in Connecticut that reached $73 \%$ of parents by training community health workers to engage in brief (1-3 minutes) interactive education modules with parents at pickup and drop-off times and in group sessions. ${ }^{46}$ A qualitative study with staff and parents using a method focused on family engagement, with solution-focused and motivational principles, found that training staff to teach and motivate parents increased the confidence of staff to work with parents around healthy lifestyle topics. ${ }^{47}$ Further research into strategies to enhance parent engagement is recommended to realize the opportunity that child care centers present as untapped resources for obesity prevention. ${ }^{48}$

This study had both strengths and limitations. Strengths include a large, diverse, statewide sample of child care centers and the use of a commonly used tool to examine nutrition/physical activity best practices in child care. The primary limitation is the low response rate $(40 \%)$, raising concerns about representation and reporting bias. It was not possible to examine factors associated with not responding as the state does not have a central database of child care center demographics. In addition, the survey examined the number of policies, provider training topics, and family education opportunities available related to nutrition/physical activity. Greater precision in each of these areas would yield additional information. Finally, this cross-sectional survey does not consider ongoing improvements in healthy weight best practices related to nutrition/physical activity.

This study provides foundational information for future studies examining specific center-based policies and rela- tionships with healthy nutrition/physical activity practices. Further descriptive research related to demographics of centers and the populations served is needed to identify variables and association with implementation of best practices. Qualitative studies exploring center-based and family environment factors would be particularly useful in learning more about the context of health-promoting practices and behaviors. In addition, studies examining HEPA practices for the youngest children in center-based care, 0-2 years of age, including a focus on breast feeding support, are needed. Finally, expanding a study such as this to include a focus on family child care homes is needed.

In conclusion, comprehensive center policies, provider training, and family education opportunities are positively associated with nutrition/physical activity best practices in child care centers, illustrating the opportunities for child care centers to contribute to healthy habits and obesity prevention among young children.

\section{Acknowledgment}

(1) CDC, Cooperative Agreement \#2B01OT009025 through the Maryland Department of Health; (2) NIH R01 DK106424; (3) NIH/NINR F31NR015399; (4) NIH/NINR T32NR012704. The contents of this publication are solely the responsibility of the authors and do not necessarily represent the official views of the Centers for Disease Control and Prevention, the Department of Health and Human Services, or the Maryland Department of Health.

\section{Author Disclosure Statement}

No competing financial interests exist.

\section{References}

1. Sorof J, Daniels S. Obesity hypertension in children: A problem of epidemic proportions. Hypertension 2002;40:441-447.

2. Collings PJ, Ball HL, Santorelli G, et al. Sleep duration and adiposity in early childhood: Evidence for bidirectional associations from the Born in Bradford Study. Sleep 2017;40. DOI: 10.1093/ sleep/zsw054

3. Di Bonito P, Pacifico L, Chiesa C, et al. Impaired fasting glucose and impaired glucose tolerance in children and adolescents with overweight/obesity. J Endocrinol Invest 2017;40:409-416.

4. Hales CM, Carroll MD, Fryar CD, Ogden CL. Prevalence of obesity among adults and youth: United States, 2015-2016. NCHS Data Brief 2017:1-8.

5. Pan L, Freedman DS, Sharma AJ, et al. Trends in obesity among participants aged 2-4 years in the Special Supplemental Nutrition Program for Women, Infants, and Children-United States, 2000 2014. MMWR Morb Mortal Wkly Rep 2016;65:1256-1260.

6. U.S. Census Bureau. Quick Facts (Maryland 2010). Available at https://wwwcensusgov/quickfacts/fact/table/MD,US/PST120217 Last accessed June 8, 2018.

7. National Resource Center for Health and Safety in Child Care and Early Education. Achieving a State of Healthy Weight: 2016 Update. University of Colorado Denver: Aurora, CO, 2017. 
8. United States Department of Agriculture. Child and Adult Care Food Program (CACFP). 2017. Available at https://wwwfnsusdagov/cacfp/child-and-adult-care-food-program Last accessed February 28, 2018.

9. Maryland State Department of Education. Nutrition Standards for Child Care: Effective October 1, 2017. Available at http://early childhoodmarylandpublicschoolsorg/system/files/filedepot/3 /nutrition_standards_for_child_care_june_2017pdf Last accessed June 8, 2018.

10. Maryland State Department of Education. Child Care Center Licensing Manual (August 2016) for use with COMAR 13A.16. Child Care Centers. Available at http://earlychildhoodmarylandpublicschoolsorg/ system/files/filedepot/3/09_program_requirementspdf Last accessed June 8, 2018.

11. Benjamin SE, Neelon B, Ball SC, Bangdiwala SI, et al. Reliability and validity of a nutrition and physical activity environmental self-assessment for child care. Int J Behav Nutr Phys Act 2007;4:29.

12. Ward DS, Vaughn AE, Mazzucca S, Burney R. Translating a child care based intervention for online delivery: Development and randomized pilot study of Go NAPSACC. BMC Public Health 2017; 17:891.

13. Ward DS, McWilliams C, Morris E. NAP SACC website. Available at https://gonapsaccorg Last accessed June 8, 2018.

14. Smith TM, Blaser C, Geno-Rasmussen C, et al. Improving nutrition and physical activity policies and practices in early care and education in three states, 2014-2016. Prev Chronic Dis 2017;14: E73.

15. Tandon PS, Walters KM, Igoe BM, et al. Physical activity practices, policies and environments in Washington State Child Care Settings: Results of a Statewide Survey. Matern Child Health J 2017;21:571-582.

16. Wolfenden L, Finch M, Nathan N, et al. Factors associated with early childhood education and care service implementation of healthy eating and physical activity policies and practices in Australia: A cross-sectional study. Trans Behav Med 2015;5:327334.

17. Federal Interagency Forum on Child and Family Statistics. America's Children: Key National Indicators of Well-Being. U.S. Government Printing Office: Washington, DC, 2013.

18. Maalouf J, Evers SC, Griffin M, Lyn R. Assessment of mealtime environments and nutrition practices in child care centers in Georgia. Child Obes 2013;9:437-445.

19. Gubbels JS, Kremers SP, Van Kann DH, et al. Interaction between physical environment, social environment, and child characteristics in determining physical activity at child care. Health Psychol 2011;30:84.

20. Benjamin Neelon SE, Vaughn A, Ball SC, et al. Nutrition practices and mealtime environments of North Carolina child care centers. Child Obes 2012;8:216-223.

21. Nanney MS, LaRowe TL, Davey C, et al. Obesity prevention in early child care settings. Health Educ Behav 2017;44:23-31.

22. Copeland KA, Sherman SN, Kendeigh CA, et al. Flip flops, dress clothes, and no coat: Clothing barriers to children's physical activity in child-care centers identified from a qualitative study. Int $J$ Behav Nutr Phys Act 2009;6:74.

23. Copeland KA, Sherman SN, Khoury JC, et al. Wide variability in physical activity environments and weather-related outdoor play policies in child care centers within a single county of Ohio. Arch Pediatr Adolesc Med 2011;165:435-442.

24. Coleman B, Dyment JE. Factors that limit and enable preschoolaged children's physical activity on child care centre playgrounds. J Early Child Res 2013;11:203-221.
25. Bronfenbrenner U. Ecological Models of Human Development. Vol. 3. 2nd ed. Oxford: Elsevier, 1994.

26. Story M, Kaphingst KM, Robinson-O’Brien R, Glanz K. Creating healthy food and eating environments: Policy and environmental approaches. Annu Rev Public Health 2008;29:253-272.

27. Child Nutrition and Women, Infants, and Children Reauthorization Act of 2004. Publ. No. 108-265, 118 Sta 729.

28. Wolfenden L, Jones J, Williams CM, et al. Strategies to improve the implementation of healthy eating, physical activity and obesity prevention policies, practices or programmes within childcare services. Cochrane Database Syst Rev 2016;10:Cd011779.

29. The YMCA of the USA. Healthy Eating and Phyiscal Activity (HEPA) Standards. Available at http://wwwymcanet/hepa Last accessed June 8, 2018.

30. Alkon A, Crowley AA, Neelon SE, et al. Nutrition and physical activity randomized control trial in child care centers improves knowledge, policies, and children's body mass index. BMC Public Health 2014;14:215.

31. Chika S, Shultz JA, Johnson SL, et al. Attitudes, concerns, and likelihood for action related to young children's overweight among early childhood program staff. Fam Commun Health 2011;34:291-300.

32. Alhassan S, Nwaokelemeh O, Ghazarian M, et al. Effects of locomotor skill program on minority preschoolers' physical activity levels. Pediatr Exerc Sci 2012;24:435-449.

33. Annesi JJ, Smith AE, Tennant GA. Effects of a cognitivebehaviorally based physical activity treatment for 4- and 5-yearold children attending US preschools. Int J Behav Med 2013;20: 562-566.

34. Ward S, Belanger M, Donovan D, Carrier N. Systematic review of the relationship between childcare educators' practices and preschoolers' physical activity and eating behaviours. Obes Rev 2015; 16:1055-1070.

35. Tucker P, van Zandvoort MM, Burke SM, Irwin JD. The influence of parents and the home environment on preschoolers' physical activity behaviours: A qualitative investigation of childcare providers' perspectives. BMC Public Health 2011;11:168.

36. Ward DS, Welker E, Choate A, et al. Strength of obesity prevention interventions in early care and education settings: A systematic review. Prev Med 2017;95 Suppl:S37-S52.

37. De Bock F, Genser B, Raat H, et al. A participatory physical activity intervention in preschools: A cluster randomized controlled trial. Am J Prev Med 2013;45:64-74.

38. Bonvin A, Barral J, Kakebeeke TH, et al. Effect of a governmentally-led physical activity program on motor skills in young children attending child care centers: A cluster randomized controlled trial. Int J Behav Nutr Phys Act 2013;10:90.

39. Herman A, Nelson BB, Teutsch C, Chung PJ. "Eat Healthy, Stay Active!": A coordinated intervention to improve nutrition and physical activity among Head Start parents, staff, and children. $\mathrm{Am}$ $J$ Health Promot 2012;27:e27-e36.

40. Ammerman AS, Ward DS, Benjamin SE, et al. An intervention to promote healthy weight: Nutrition and Physical Activity SelfAssessment for Child Care (NAP SACC) theory and design. Prev Chronic Dis 2007;4:A67.

41. Sigman-Grant M, Christiansen E, Fernandez G, et al. Peer reviewed: Child care provider training and a supportive feeding environment in child care settings in 4 states, 2003. Prev Chronic Dis 2011;8:A113.

42. Liu ST, Graffagino CL, Leser KA, et al. Obesity prevention practices and policies in child care settings enrolled and not enrolled in the Child and Adult Care Food Program. Matern Child Health $J$ 2016;20:1933-1939. 
43. Lyn R, Maalouf J, Evers S, et al. Peer reviewed: Nutrition and physical activity in child care centers: The impact of a wellness policy initiative on environment and policy assessment and observation outcomes, 2011. Prev Chronic Dis 2013;10:E83.

44. Erinosho TO, Hales DP, McWilliams CP, et al. Nutrition policies at child-care centers and impact on role modeling of healthy eating behaviors of caregivers. J Acad Nutr Diet 2012;112:119124.

45. Dwyer J, Needham L, Simpson JR, Heeney ES. Parents report intrapersonal, interpersonal, and environmental barriers to supporting healthy eating and physical activity among their preschoolers. Appl Physiol Nutr Metab 2008;33:338-346.

46. Cloutier MM, Wiley JF, Trapp C, et al. The Childcare Center: An untapped opportunity to engage and educate families in healthy behaviors. J Racial Ethn Health Disparities 2018;5:430-438.

47. Willis TA, Potrata B, Hunt C, Rudolf MC. Training community practitioners to work more effectively with parents to prevent childhood obesity: The impact of HENRY upon Children's Centres and their staff. J Hum Nutr Diet 2012;25:460-468.

48. Kaphingst KM, Story M. Child care as an untapped setting for obesity prevention: State child care licensing regulations related to nutrition, physical activity, and media use for preschool-aged children in the United States. Prev Chronic Dis 2009;6:A11.

Address correspondence to: Erin R. Hager, PhD Department of Pediatrics University of Maryland School of Medicine 737 West Lombard Street, Room 163 Baltimore, MD 21201

E-mail: ehager@som.umaryland.edu 